\title{
Editorial
}

\section{Advances in Solidification Processing}

\author{
Hugo F. Lopez \\ Department of Materials Science and Engineering, CEAS, University of Wisconsin-Milwaukee, \\ 3200 N. Cramer Street, Milwaukee, WI 53211, USA; E-Mail: hlopez@uwm.edu; \\ Tel.: +1-414-229-6005; Fax: +1-414-229-6958
}

Received: 24 July 2015 / Accepted: 24 July 2015 / Published: 11 August 2015

\begin{abstract}
Melt solidification is the shortest and most viable route to obtain components, starting from the design to the finished products. Hence, a sound knowledge of the solidification of metallic materials is essential for the development of advanced structural metallic components that drive modern technological societies. As a result, there have been innumerable efforts and full conferences dedicated to this important subject [1-6]. In addition, there are various scientific journals fully devoted to investigating the various aspects which give rise to various solidification microstructures [7-9]. Since a homogeneous solidified microstructure is highly desirable, novel approaches have been implemented to have a close control of the heat flow from the liquid-solid interface and towards the surrounding mold walls [10,11]. Since the solidified microstructure determines the properties of the castings, the various micro-mechanisms, which account for the exhibited casting properties, are been investigated at all the length scales (macro-, micro-, and nano-levels) [12,13]. In particular, significant advances in solidification have been achieved through analytical and computer simulation modeling using transformation kinetics for the solid-liquid and solid-solid transformations. Also, through advances in the use of modern computer technologies, it is now possible to predict by numerical mathematical modeling the metallurgical aspects of the microstructural evolution $[13,14]$. There are currently powerful simulation packages available in the market such as Magma [15], which incorporate complex mold shapes and are able to identify locations of potential problems for the integrity of the cast part. However, we are still far from a complete prediction of the total solidification process including the location and type of defects in the final part, due to the tremendous magnitude of the computational requirements. Advances in solidification science are ongoing, as found in some fundamental work using phase-field simulations of solidification process [16].
\end{abstract}

\section{The Present Issue}

I am honored to be the Guest Editor for the first time of a thematic issue published in the journal Metals. In this first issue, four articles are dedicated to the science and engineering of cast iron, particularly nodular irons, a review paper and an article are both focused on the solidification of the solid structure 
from the melt under non-equilibrium conditions and one on simulation of mechanical properties in a squeezed cast aluminum alloy. Accordingly, the work of Escobar et al. [17] investigates the effect of pouring temperature and cooling rates on the nodular count. They find good agreement between the simulation and the experimental outcome. Naxtiondo et al. [18] further investigate the effect of solidification in nodular iron by employing Quenching experiments on two different carbon equivalent compositions using inoculated and non-inoculated iron. They found structural features at different locations of each sample and at different stages of solidification. Also, the nodule evolution was analyzed and discussed in this work. Additional work on nodular cast iron was presented by Song et al. [19]. In their work, they investigate the role of $\mathrm{Si}$ on the mechanical properties and fracture toughness exhibited in heavy sections of nodular iron. The work by Fras et al. [20] provides a means to analytically predict the resultant cast iron microstructure as a function of alloying elements such as $\mathrm{Si}, \mathrm{Mn}, \mathrm{S}$ and others. Their work shows that the analytical model is highly accurate for predictions of expected cast iron microstructures and properties. With regards to non-equilibrium solidification from the melt, D. M. Herlach [21] uses containerless processing by electromagnetic and electrostatic levitation to avoid heterogeneous nucleation effects and thus promote solidification under large undercoolings and away from equilibrium. The exhibited evolution of the solidified microstructure (nucleation and growth) is followed by x-ray diffraction means. A. M. Mullis [22] also considers a non-equilibrium solidification model using phase field simulation. In his work, he describes how the application of such a model can help explain the long-standing phenomenon of spontaneous grain refinement in deeply undercooled melts. Finally, Souissi et al. [23] employ the Taguchi method to investigate the relationship between the ultimate tensile strength, hardness and process variables in a squeeze casting 2017 A wrought aluminum alloy. The aim of their work is to establish an optimal combination of process parameters and a reduction in alloy quality variation.

I would especially like to thank Jane Zhang, Managing Editor for her support and active role in the publication of this first issue on Advances in Solidification Processing. I am also grateful to the entire staff of the Metals Editorial Office, who productively collaborated on this endeavor. Furthermore, I would like to thank all of the authors contributing their papers to this issue for their excellent work.

Although, in this first issue various important aspects related to advanced solidification processing have been addressed, there is still a big challenge in bringing together expertise and knowledge on the state of the art both in computer modeling and in experimental work focused on advanced solidification issues. Hopefully, further issues in this field will enable the dissemination of novel research aimed at advancing the understanding of solidification science.

\section{References and Notes}

1. Smith, C.L.; Bolling, G.F.; Kerr, H.W.; Cole, G.S. A survey of solidification and casting literature up to MID 1969. Scr. Metal 1970, 4, 445-450.

2. Solidification and Casting of Metals. In Proceedings of the International Conference on Solidification, Sheffield Metallurgical Engineering Association, University of Sheffield, Metals Society, London, UK, 1979. 
3. Solidification 1998. In Proceedings of the Symposia Sponsored by the Solidification Committee of the Materials Design and Manufacturing Division of TMS, Indianapolis, IN, USA, 15-18 September 1997.

4. Stefanescu, D. Modeling of Casting, Welding and Advanced Solidification Processes X; 2003.

5. Proceedings of the Liquid Metal Processing \& Casting Conference 2015, Leoben, Austria, 2015.

6. Desch, C.H. Beilby Prize Committee of the Institute of Metals on "The Solidification of Metals from the Liquid State". Nature 2014, 93, 674-674.

7. All papers published in International Journal of Cast Metals Research in 2015.

8. All papers published in International Journal of Metalcasting in 2015.

9. All papers published in Journal of Crystal Growth in 2015.

10. Fraś, E.; Górny, M.; Lopez, H. Thin wall ductile and austempered iron castings as substitutes for aluminium alloy casting. Int. Foundry Res./Giessereiforschung 2009, 3, 34-42.

11. Fras, E.; Gorny, M.; Lopez, H.F. Thin wall ductile and austempered iron castings as substitutes for aluminium castings. Foundry Trade J. Int. 2011, 185, 85-90.

12. Stefanescu, D.M. Science and Engineering of Casting Soildification; Kluwer Academic Press, 2002.

13. The Science of Casting and Solidification. Stefanescu, D.M., Ruxanda, R., Tierean, M., Serban, C., Eds.; 2001; Brasov, Transilvania, Romania.

14. Munteanu, S.I. Computer-aided simulation of aluminum alloys solidification in continuous electromagnetic casting. Stefanescu, D.M., Ruxanda, R., Tierean, M., Serban, C., Eds.; 2001; pp. 151-157. Brasov, Transilvania, Romania.

15. Magma Engineering. Germany.

16. Boettinger, W.J.; Warren, J.A.; Beckermann, C.; Karma, A. Phase-field simulation of solidification. Annu. Rev. Mater. Res. 2002, 32, 163-194.

17. Escobar, A.; Celentano, D.; Cruchaga, M.; Bernd, S. On the Effect of Pouring Temperature on Spheroidal Graphite Cast Iron Solidification. Metals 2015, 5, 628-647.

18. Natxiondo, A.; Suárez, R.; Sertucha, J.; Larrañaga, P. Graphite and Solid Fraction Evolutions during Solidification of Nodular Cast Irons. Metals 2015, 5, 239-255.

19. Song, L.; Guo, E.; Wang, L.; Liu, D. Effects of Silicon on Mechanical Properties and Fracture Toughness of Heavy-Section Ductile Cast Iron. Metals 2015, 5, 150-161.

20. Fraś, E.; Lopez, H.F.; Kawalec, M.; Gorny, M. Role of Alloying Additions in the Solidification Kinetics and Resultant Chilling Tendency and Chill of Cast Iron. Metals 2015, 5, 256-288.

21. Herlach, D.M. Non-Equilibrium Solidification of Undercooled Metallic Melts. Metals 2014, 4, 196-234.

22. Mullis, A.M. The Origins of Spontaneous Grain Refinement in Deeply Undercooled Metallic Melts. Metals 2014, 4, 155-167.

23. Souissi, N.; Souissi, S.; Niniven, C.L.; Amar, M.B.; Bradai, C.; Elhalouani, F. Optimization of Squeeze Casting Parameters for 2017 A Wrought Al Alloy Using Taguchi Method. Metals 2014, 4, 141-154.

(C) 2015 by the authors; licensee MDPI, Basel, Switzerland. This article is an open access article distributed under the terms and conditions of the Creative Commons Attribution license (http://creativecommons.org/licenses/by/4.0/). 